\title{
Impacto da antropização na qualidade da água e no solo de áreas ciliares avaliado em uma bacia hidrográfica na região Sul do Brasil
}

\author{
Assessed impact of anthropization on water and soil quality in a drainage basin in \\ southern Brazil
}

\author{
Filipe Antonio Wroblescki*, Ildegardis Bertol, Neuro Hilton Wolschick, Bárbara Bagio, Venesa Pinto \\ dos Santos, Loriane Bernardi, Luiz Antonio Biasiolo
}

Universidade do Estado de Santa Catarina, Lages, SC, Brasil. *Autor para correspondência: filipe.wroblescki@lages.sc.gov.br

Submissão: 10/07/2019 / Aceite: 10/12/2020

\begin{abstract}
RESUMO
A antropização de ambientes terrestres tem aumentado a produção de nutrientes e de compostos orgânicos e o aporte dos mesmos nas águas superficiais e no solo localizado nas margens das mesmas, ocasionado alterações na qualidade da água e do solo. Com o objetivo de avaliar o impacto da antropização no ambiente ciliar, foi realizada análise de fósforo, potássio e carbono na água, bem como de fósforo, potássio e matéria orgânica no solo, em 18 locais, respectivamente, na água do Ribeirão Petrópolis e no solo às suas margens, numa bacia hidrográfica na cidade de Lages, SC, Brasil. As coletas de amostras de água foram realizadas em agosto e dezembro de 2016, e em março e junho de 2017. As coletas de amostras de solo ocorreram apenas em agosto de 2016 e junho de 2017. Os locais amostrados situavam-se em áreas de floresta, campo nativo e área urbana. $O$ fósforo e potássio dissolvido na água foram determinados conforme metodologia descrita por MURPHY \& RILEY (1962), enquanto o carbono dissolvido em água foi mineralizado por combustão em forno a $800{ }^{\circ} \mathrm{C}$ e determinado em TOC/TN Analytik Jena Multi N/C 2100. Já fósforo e potássio extraível do solo e matéria orgânica foram determinados conforme medologias descritas em TEDESCO et al. (1995). Observou-se que a concentração de fósforo, potássio e carbono dissolvido na água foi maior no trecho do rio que passava pela área urbana do que naquele que passava pelo campo e pela floresta, em praticamente todas as épocas do ano. $\mathrm{O}$ mesmo comportamento ocorreu com o fósforo e potássio no solo às margens do rio. Entretanto, o teor de matéria orgânica no solo foi menor no trecho que passava pela área da cidade. Os resultados dessa pesquisa apontaram que na área urbana, onde o tratamento de esgoto não era realizado, ou era deficitário, o lançamento de efluentes domésticos contendo detergentes fosfatados e sabões acarretaram no aumento do fósforo, potássio e carbono na água e de fósforo e potássio no solo.
\end{abstract}

PALAVRAS-CHAVE: efluente doméstico, uso e ocupação da terra, aporte de carbono e nutrientes.

\begin{abstract}
The anthropization of terrestrial environments has increased the production and concentration of nutrients and organic compounds in shallow bodies of water and in the soil along river banks, thereby causing changes in both water and soil quality. To examine the impact of anthropization on river environments, the phosphorus, potassium, and carbon content in the water and the phosphorus, potassium, and organic matter in the soil were analyzed at eighteen sites. The experimental area is located in an urbanized drainage basin located in the municipality of Lages, Santa Catarina (southern Brazil). The water samples were collected in two field surveys. The first one occurred between August and December 2016, and the second took place from March to June 2017. The soil samples were collected in one field survey from August 2016 and June 2017. The 18 sites were regularly distributed across forests, native grasslands, and urban areas. The dissolved phosphorus and potassium in the water were obtained by applying the methodology proposed by MURPHY \& RILEY (1962), whereas the dissolved carbon in the water was mineralized by combustion using an oven at $800{ }^{\circ} \mathrm{C}$ and calculated with the Analytik Jena Multi N/C 2100 TOC/TN Analyzer. On the other hand, the extractable phosphorus and potassium from the soil and organic matter were determined with the methodology described by TEDESCO et al. (1995). The results demonstrated that the concentration of dissolved phosphorus, potassium, and carbon in the water was greater in the parts of the river that cross through urban areas than in the parts of the river that course through grasslands and forests throughout practically the entire year. The same trend was observed with the phosphorus and potassium content in the soil along the river banks. However, the organic matter
\end{abstract}


content in the soil was lower in the sections located in urban areas. The findings indicate that in urban areas where sewage treatment is either nonexistent or deficient, the release of domestic wastewater containing household detergents and soaps contributes to the increase in the content of phosphorus, potassium, and carbon in the water and phosphorus and potassium in the soil.

KEYWORDS: domestic wastewater, land use and occupancy, concentration of carbon and nutrients.

\section{INTRODUÇÃO}

Os nutrientes são essenciais para a manutenção da vida, mas, quando estão presentes em excesso no solo ou na água podem constituir-se em fator poluente. No caso da água, quando a quantidade de nutrientes é superior a capacidade assimilativa do corpo hídrico acarreta o processo químico/biológico caracterizado como eutrofização. Assim, segundo VON SPERLING (2005), a eutrofização é um processo aquático negativo que normalmente é resultante de atividade antrópica que desencadeia problemas estéticos recreacionais, floração de algas, aumento do consumo de oxigênio, distúrbio com mosquitos e demais insetos, maus odores e crescimento excessivo da vegetação.

As fontes antrópicas de origem urbana são as que têm maior capacidade de poluição das águas superficiais por nutrientes. Essas fontes provêm de rejeitos sólidos (lixões) inapropriadamente acomodados, de águas servidas (esgotamento sanitário) emitidas no meio ambiente sem tratamento prévio e de escoamento superficial urbano (PAULA et al. 2010). O crescimento urbano e populacional desordenado faz com que essas áreas lancem grande quantidade de resíduos nos mananciais. De modo geral, a população urbana de baixa renda que é também de baixo nível educacional e econômico, é o potencial agente ativo e passivo causador de danos ambientais, o que se reflete na saúde e no bem-estar da sociedade como um todo (SILVA \& FONSECA 2016). Além disso, locais urbanos com elevada e consolidada concentração de pessoas, poucas e ineficazes políticas públicas são adotadas para investir na implantação ou manutenção de sistemas de saneamento.

Estudos para determinar a concentração de fósforo $(\mathrm{P})$, potássio $(\mathrm{K})$ e carbono $(\mathrm{C})$ na água dos rios e de $\mathrm{P}, \mathrm{K}$ e matéria orgânica (MO) no solo às suas margens, em áreas urbanas, permitem inferir sobre a dinâmica desses nutrientes nesses ambientes. A inundação de áreas alagáveis faz com que haja a deposição de sedimentos e, com isso, as áreas alagadas são enriquecidas com nutrientes trazidos pela enxurrada (SOUZA \& ALMEIDA 2010). A utilização de bacia hidrográfica como unidade física nesse tipo de estudo permite uma visão sistêmica e integrada do ambiente, o que reforça a ideia de que a bacia é unificadora dos processos ambientais e das interferências humanas que nela ocorrem (CARVALHO 2014).

Com este estudo objetivou-se determinar e correlacionar o $\mathrm{P}$, o $\mathrm{K}$ e o $\mathrm{C}$ dissolvidos na água e o $\mathrm{P}$ e $\mathrm{K}$ extraível e a $\mathrm{MO}$ do solo, respectivamente, no ribeirão Petrópolis e no solo às suas margens, numa bacia hidrográfica localizada na cidade de Lages, em Santa Catarina, Brasil.

\section{MATERIAL E MÉTODOS}

O estudo foi realizado na bacia hidrográfica do Ribeirão Petrópolis, situada nas proximidades da cidade de Lages incluindo parte da área urbana, no estado de Santa Catarina e que não possui classe definida conforme Resolução CONAMA 357, de março de 2005. A bacia está localizada entre as

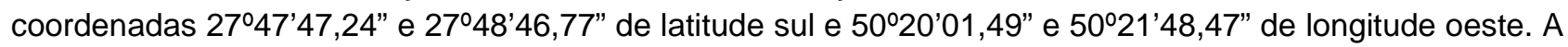
área é de $2,86 \mathrm{~km}^{2}$ com perímetro de $12,26 \mathrm{~km}$, cujo tributário principal que drena a bacia mede $4,16 \mathrm{~km}$ de extensão. A altura de chuva total precipitada durante o tempo de estudo foi de $1.689 \mathrm{~mm}$, com média mensal de $169 \mathrm{~mm}$, em que a menor altura, $82 \mathrm{~mm}$, ocorreu em novembro de 2016, enquanto, a maior, 359 $\mathrm{mm}$, em maio de 2017 (CEMADEN 2018).

Foram coletadas amostras de 18 locais na área da bacia, visando obter representatividade do efeito do uso e ocupação da terra sobre a qualidade da água e do solo na área da bacia. Sete locais na área de floresta foram identificados como 1, 2, 3, 4, 5, 7 e 12 (Figura 1). Na área de campo apenas dois locais foram coletadas amostras ( 6 e 9), pelo fato de ter sido constatada baixa intensidade de exploração agropecuária, não justificando assim maior densidade de amostragem. $\mathrm{Na}$ área urbana, com alta antropização pelo fato não existir tratamento de esgoto, ou por ele ser deficitário, a amostragem foi realizada em oito locais a jusante da floresta $(10,11,13,14,15,16,17$ e 18) e um a montante (8).

A amostragem da água foi realizada em agosto e dezembro de 2016, e em março e junho de 2017. Nos 18 locais da bacia (Figura 1) foram coletadas 22 amostras em cada data, totalizando 88 amostras no período de estudo. Em quatro locais (1, 11, 12 e 17) havia confluência de cursos d'água. Por isso, nesses casos, em cada uma das confluências foi realizada uma amostragem. As amostras foram recolhidas às 
margens dos cursos d'água, próximo da superfície da lâmina d'água, usando frascos de plástico de $200 \mathrm{ml}$, com tampa de rosca. Os frascos com a água foram armazenados em congelador. Posteriormente a água foi filtrada em papel poroso com malha $0,45 \mu \mathrm{m}$. Na sequência o fósforo dissolvido em água (FDA) e potássio dissolvido em água (PDA), foram extraídos pelo método de MURPHY \& RILEY (1962). A determinação de FDA foi realizada em espectrofotômetro de absorção molecular na região do visível em $882 \mathrm{~nm}$, e a do PDA em espectrofotômetro de emissão atômica em chamas. O carbono dissolvido em água (CDA) foi mineralizado por combustão em forno a $800 \stackrel{\circ}{\circ}$ e e determinado em TOC/TN Analytik Jena Multi N/C 2100.

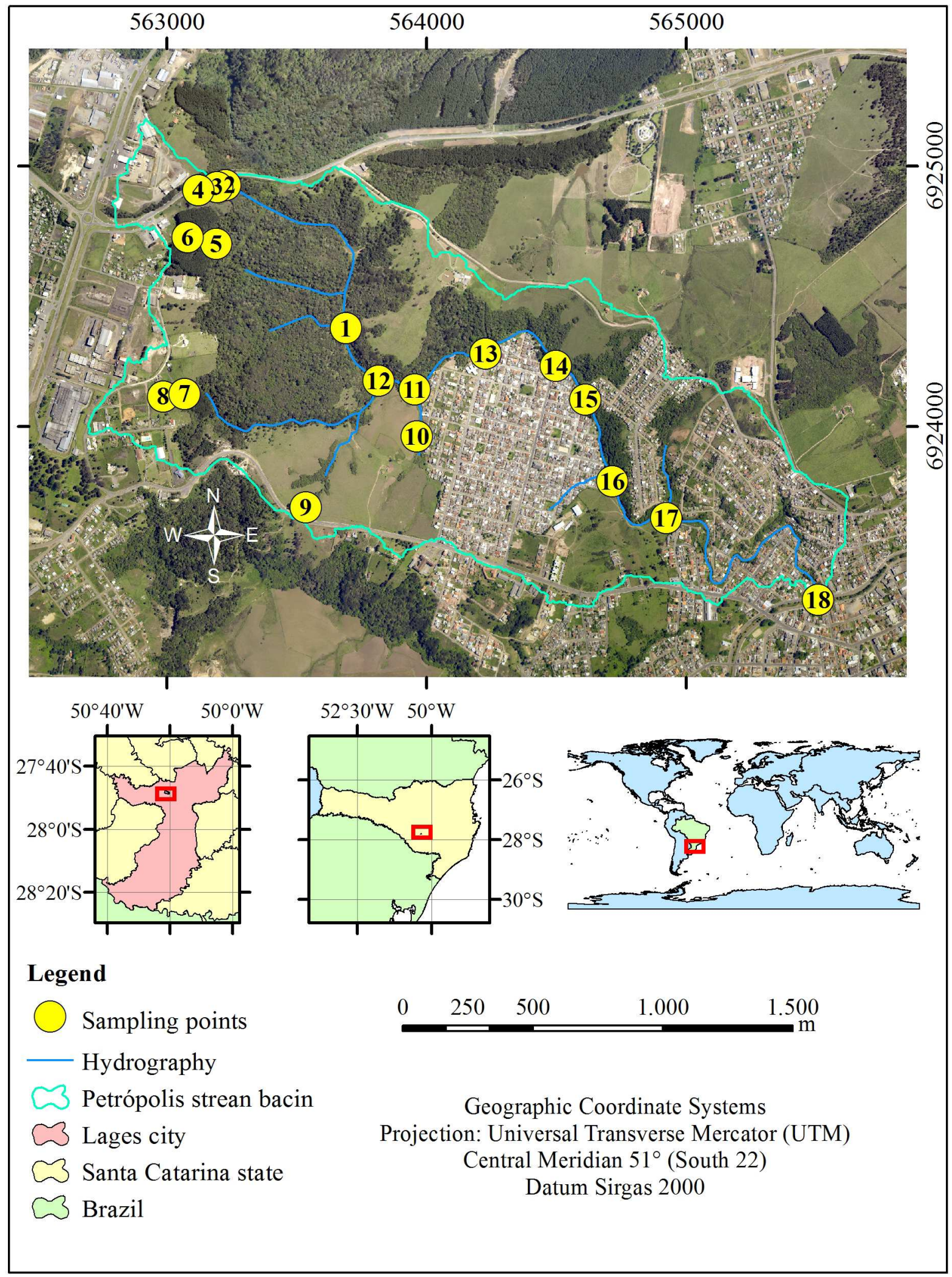

Figura 1. Localização da área de estudo e indicação dos 18 locais de amostragem na bacia hidrográfica do Ribeirão Petrópolis. 
A amostragem do solo foi realizada em agosto de 2016 e junho de 2017, presumindo-se que não haveria diferença de concentração de $\mathrm{P}, \mathrm{K}$ e $\mathrm{MO}$ no solo entre uma e outra estação climática do ano. Nos 18 locais da bacia (Figura 1) foram coletadas 18 amostras do solo em cada data, totalizando 36 amostras no período de estudo. As amostras foram coletadas às margens dos cursos d'água, em camada superficial (0-3 $\mathrm{cm})$. Devido a variabilidade natural do solo, cinco sub-amostras foram coletadas em cada local para constituir a amostra do referido local. O solo foi seco ao ar, destorroado com rolo metálico, peneirado em malha de $2 \mathrm{~mm}$ e acondicionado em sacos plásticos transparentes. Antes do final do período de estudo as amostras foram enviadas ao Laboratório de Análises Químicas do Solo da UDESC/CAV. O fósforo extraível do solo (FES) e o potássio extraível do solo (PES) foram determinados pelo método Mehlich-1, e a matéria orgânica do solo (MOS) pelo método da solução sulfocrômica, descritos em TEDESCO et al. (1995). A determinação do FES e MOS foi realizada em espectrofotometria de absorção molecular em $660 \mathrm{~nm}$ e do PES em espectrofotômetro de emissão atômica em chamas.

A altura de chuva natural foi registrada em pluviômetro localizado nas dependências do CAV/UDESC, distante aproximadamente $2.500 \mathrm{~m}$ da bacia hidrográfica estudada, para demonstrar a possível influência das precipitações nos dados coletados.

Neste trabalho, por se tratar de estudo exploratório, foi realizada análise de agrupamento pelo método hierárquico utilizando distância Euclidiana como medida de similaridade entre os pontos de coleta. $O$ método de Ward foi empregado como procedimento que resulta em agrupamentos de tamanhos aproximadamente iguais devido a sua minimização de variação interna. Além disso, utilizou-se matriz de correlação para identificar possível relação entre os parâmetros analisados. Todas as análises estatísticas foram realizadas no aplicativo Action Stat Pro integrado com o MS-Excel.

\section{RESULTADOS E DISCUSSÃO}

\section{Chuvas ocorridas no período da pesquisa}

Durante a pesquisa, ocorreram 43 eventos de precipitação (i.e. chuvas), totalizando $746,9 \mathrm{~mm}$, com variação de 0,20 a 117,4 mm entre uma e outra, em intervalo de tempo que variou desde um dia até 28 dias antecedente às datas de coleta dos dados, (Tabela 1). Desse modo, antes da $1^{\underline{a}}$ data de coleta (16/08/2016), havia precipitado $130,5 \mathrm{~mm}$ de chuva, e entre a $1^{\mathrm{a}}$ e a $2^{\mathrm{a}}$ coleta a precipitação totalizou 80,6 $\mathrm{mm}$. Esse total foi de $68,2 \mathrm{~mm}$ entre a $2^{\mathrm{a}}$ e a $3^{\mathrm{a}}$ coleta e de $467,6 \mathrm{~mm}$ antes da $4^{\mathrm{a}}$ e última coleta. Essas alturas de chuva, assim distribuídas, podem ter influenciado a concentração dos nutrientes na água do rio.

\section{Fósforo dissolvido na água (FDA)}

$\mathrm{O}$ teor de FDA variou entre 0,01 e $2,50 \mathrm{mg} \mathrm{L}^{-1}$ (250 vezes), considerando os locais de coleta das amostras, as formas de uso da terra e as épocas de coleta, com os maiores valores tendendo a ocorrer nos locais onde o rio passava pela área urbana, portanto, antropizada (Tabela 2). Considerando as formas de uso da terra, o teor de FDA na parte urbana do rio foi 15,4 vezes maior do que no campo e sete vezes maior do que na floresta, na média dos locais e das épocas de coleta. Isso demonstra o elevado grau de contaminação das águas por $\mathrm{P}$ nos locais do rio em que antropização é elevada, principalmente devido ao livre lançamento de efluentes domésticos diretamente no leito do rio.

No caso da época de amostragem, a variação de FDA foi de 2,1 vezes entre o menor e o maior valor, na média das formas de uso da terra e dos locais de amostragem. Essa diferença foi mais acentuada quando as amostras foram coletadas em junho de 2017, podendo estar relacionada com efeito do clima, como a forte incidência de chuva $(467,57 \mathrm{~mm}$ ) que aconteceu 28 dias antes da amostragem (Tabela 1), fazendo com que houvesse maior aporte de $\mathrm{P}$ para os cursos hídricos, não observando em outros períodos variação significantes das concentrações como o que ocorreu na área urbana. Segundo OISHI (1996), nas áreas urbanas, as concentrações de contaminantes normalmente aumentam em função do acréscimo da porcentagem de áreas impermeabilizadas.

A resolução CONAMA 357/2005 (BRASIL 2005) estabeleceu parâmetros numéricos para o enquadramento de água doce segundo o padrão de qualidade, quanto ao teor de $\mathrm{P}$ nas águas do território nacional. Dentre as 88 amostras de água do Ribeirão Petrópolis analisadas, em 38 a concentração de FDA foi baixa e permitiu enquadrar a água como classe 1, enquanto em apenas oito das mesmas a água estava enquadrada na classe 3 e em 42 na classe 4 . Na área de floresta, em 23 amostras a água se enquadrou na classe 1 , em cinco na classe 3 e em oito na classe 4. No campo, em todas as amostras a água se enquadrou na classe 1, enquanto, na área urbana, em sete amostras a água se enquadrou na classe 1, em oito na classe 3 e em 34 na classe 4.

Foi possível verificar que as concentrações de $\mathrm{P}$ foram maiores na parte urbana do que nas demais formas de uso da terra (Tabela 2). Outros autores também constataram como no caso da bacia do Rio Tietê 
em São Paulo, que o impacto da antropização em área urbana concorreu para aumentar a concentração de $\mathrm{P}$, tornando-a expressivamente elevada comparativamente à atividade agrícola (QUEVEDO \& PAGANINI 2011). Segundo os autores, a inquestionável presença de detergentes no esgoto doméstico, em magnitude elevada, contribuiu para a configuração desse cenário.

Tabela 1. Chuva ocorrida antes da realização da amostragem da água no Ribeirão Petrópolis e no solo às suas margens, em Lages, SC.

\begin{tabular}{|c|c|c|c|c|}
\hline \multirow{2}{*}{$\begin{array}{c}\text { Número de dias antes da } \\
\text { amostragem }\end{array}$} & \multicolumn{4}{|c|}{ Chuvas } \\
\hline & Ago-16 & Dez-16 & Mar-17 & Jun-17 \\
\hline & & & ---------- & \\
\hline 28 & 6,3 & 35,0 & - & 69,0 \\
\hline 27 & 0,2 & 2,2 & - & 35,4 \\
\hline 26 & - & - & - & 24,4 \\
\hline 25 & - & - & - & 40,4 \\
\hline 24 & - & - & - & 67,7 \\
\hline 23 & - & - & - & 11,2 \\
\hline 22 & - & - & - & - \\
\hline 21 & - & - & 9,8 & - \\
\hline 20 & 18,3 & - & 19,1 & 117,4 \\
\hline 19 & 0,6 & - & 24,6 & 65,2 \\
\hline 18 & - & - & 2,2 & 3,7 \\
\hline 17 & - & 1,6 & 3,0 & 15,8 \\
\hline 16 & - & 1,4 & - & 9,9 \\
\hline 15 & - & - & - & 3,4 \\
\hline 14 & - & - & - & - \\
\hline 13 & - & - & - & - \\
\hline 12 & 24,4 & - & - & - \\
\hline 11 & - & 3,9 & - & - \\
\hline 10 & 10,8 & 0,4 & - & - \\
\hline 9 & 0,2 & - & - & - \\
\hline 8 & 18,3 & - & 3,0 & - \\
\hline 7 & 35,9 & - & - & - \\
\hline 6 & 15,4 & 11,2 & - & - \\
\hline 5 & - & 19,7 & - & 4,0 \\
\hline 4 & - & 5,0 & - & - \\
\hline 3 & - & - & 4,4 & - \\
\hline 2 & - & - & 0,6 & 0,2 \\
\hline 1 & - & 0,2 & 1,6 & - \\
\hline Total & 130,5 & 80,6 & 68,2 & 467,6 \\
\hline
\end{tabular}

Em outro trabalho, ALVIM (2016) também constatou maiores concentrações de $P$ no trecho da área urbana do Rio Piracicaba em São Paulo; valores intermediários foram constatados no trecho das áreas agrícolas e, os menores, no trecho de cabeceira do mesmo rio, onde a cobertura do solo ainda era de floresta nativa. Segundo este autor, o impacto da antropização estava relacionado, principalmente, à precária infraestrutura de coleta e tratamento de esgotos domésticos nos municípios pertencentes à bacia hidrográfica do referido rio e, com menos importância, às atividades agrícolas.

\section{Potássio dissolvido na água (PDA)}

O PDA variou entre 0,5 e 17,4 $\mathrm{mg} \mathrm{L}^{-1}$ (Tabela 2). Os maiores valores de $\mathrm{K}$ tenderam ocorrer nos locais onde o rio passava pela área urbana. Analisando as formas de uso da terra, o teor de PDA no trecho urbano do rio foi 2,4 vezes maior do que passava pelo campo e 1,7 vezes maior do aquele que passava pela floresta, na média dos locais e das épocas de coleta. A elevação do teor de $\mathrm{K}$ na água do rio que passava pela área urbana ocorreu principalmente devido ao lançamento do esgoto doméstico com sabões constituídos de sais de sódio e potássio de diversos ácidos graxos, conforme constatado também por OSORIO \& OLIVEIRA (2001). Também foi cogitado a possibilidade da grande quantidade de precipitação ocorrido antes da amostragem de junho de 2017 (Tabela 1), tenham influenciado o aumento da concentração de PDA na área urbana do que para os outros usos da terra.

Ainda foi possível constatar que as maiores concentrações de $\mathrm{K}$ na água ocorreram na área urbana (Tabela 2). Outros autores também observaram o mesmo comportamento, como no caso do Rio Verde em Ponta Grossa, PR, onde os teores foram maiores na parte urbana do que na parte rural (SEQUINEL et al. 2011). Segundos os autores, essa elevação de $\mathrm{K}$ na água no aporte urbano foi influenciada por despejo de 
efluentes de origem residencial. Em outro trabalho, SANTOS et al. (2009) encontraram valores médios de $7,24 \mathrm{mg} \mathrm{L}^{-1}$ de $\mathrm{K}$ para o período de dezembro de 2005 a julho de 2007, nas águas do Rio de Contas na parte urbana da cidade de Jequié, BA, portanto, semelhantes aos verificados no ribeirão Petrópolis. $\mathrm{Na}$ área de floresta, foram encontrados valores de concentração de $\mathrm{K}$ variando de 1,6 a 6,1 $\mathrm{mg} \mathrm{L}^{-1}$, com média de $3,1 \mathrm{mg} \mathrm{L}^{-1}$ (Tabela 1), maiores, portanto, do que os verificados por SANTOS et al. (1984) para os afluentes do Rio Negro e Pires, Vaitsman e Dutra (2007) para o Parque Nacional da Serra dos Órgãos e entorno, cujas concentrações obtidas por esses autores não excederam $1,3 \mathrm{mg} \mathrm{L}^{-1}$.

Tabela 2. Valores de concentração de fósforo, potássio e carbono dissolvido na água do Ribeirão Petrópolis, em Lages, SC, divididos por grupo $(\mathrm{G})$ de ponto $(\mathrm{P})$ de coleta formado com base na análise de agrupamento.

\begin{tabular}{|c|c|c|c|c|c|c|c|c|c|c|c|c|c|c|c|c|}
\hline \multirow[b]{2}{*}{$\mathrm{G} / \mathrm{P}$} & \multirow{2}{*}{$\begin{array}{l}\text { Uso do } \\
\text { solo }\end{array}$} & \multicolumn{5}{|c|}{ Fósforo Dissolvido } & \multicolumn{5}{|c|}{ Potássio Dissolvido } & \multicolumn{5}{|c|}{ Carbono Dissolvido } \\
\hline & & $\begin{array}{c}\text { Ago- } \\
16\end{array}$ & $\begin{array}{c}\text { Dez- } \\
16\end{array}$ & $\begin{array}{c}\text { Mar- } \\
17\end{array}$ & $\begin{array}{c}\text { Jun- } \\
17\end{array}$ & Média & $\begin{array}{c}\text { Ago- } \\
16\end{array}$ & $\begin{array}{l}\text { Dez } \\
-16\end{array}$ & $\begin{array}{c}\text { Mar- } \\
17\end{array}$ & $\begin{array}{c}\text { Jun- } \\
17\end{array}$ & Média & $\begin{array}{l}\text { Ago- } \\
16\end{array}$ & $\begin{array}{c}\text { Dez- } \\
16\end{array}$ & $\begin{array}{c}\text { Mar- } \\
17\end{array}$ & $\begin{array}{c}\text { Jun- } \\
17\end{array}$ & Média \\
\hline & & ------. & 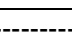 & 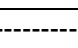 & ---- & 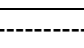 & ---. & $-\cdots$ & 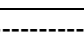 & $--m g$ & 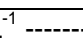 & --- & -- & ---. & 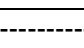 & \\
\hline $\begin{array}{l}\text { l/1- } \\
\text { direta }\end{array}$ & Floresta & 0.04 & 0.06 & 0.08 & 0.22 & 0.10 & 1.9 & 2.4 & 3.0 & 2.7 & 2.5 & 4.8 & 11.2 & 13.2 & 9.3 & 9.6 \\
\hline $\begin{array}{c}\text { I/1- } \\
\text { esquerda }\end{array}$ & Floresta & 0.11 & 0.05 & 0.04 & 0.06 & 0.07 & 1.2 & 2.4 & 1.2 & 1.5 & 1.6 & 4.0 & 6.6 & 8.3 & 5.1 & 6.0 \\
\hline $1 / 3$ & Floresta & 0.04 & 0.12 & 0.10 & 0.12 & 0.11 & 3.6 & 3.8 & 2.4 & 3.5 & 3.3 & 10.4 & 12.4 & 13.8 & 8.5 & 11.3 \\
\hline $1 / 4$ & Floresta & 0.05 & 0.02 & 0.05 & 0.04 & 0.04 & 5.7 & 4.0 & 2.9 & 2.3 & 3.7 & 20.4 & 20.1 & 6.1 & 4.7 & 12.8 \\
\hline $\mathrm{I} / 5$ & Floresta & 0.06 & 0.08 & 0.07 & 0.06 & 0.07 & 5.1 & 3.2 & 2.6 & 2.8 & 3.4 & 20.0 & 4.0 & 3.5 & 4.2 & 7.9 \\
\hline $\begin{array}{l}\text { l/12- } \\
\text { direta }\end{array}$ & Floresta & 0.08 & 0.20 & 0.11 & 0.08 & 0.12 & 2.4 & 2.4 & 2.0 & 2.3 & 2.3 & 8.1 & 10.4 & 10.5 & 8.5 & 9.4 \\
\hline $\begin{array}{l}\text { I/12- } \\
\text { esquerda }\end{array}$ & Floresta & 0.06 & 0.05 & 0.04 & 0.02 & 0.04 & 1.9 & 2.7 & 1.9 & 2.6 & 2.3 & 7.8 & 10.7 & 13.1 & 8.0 & 9.9 \\
\hline $11 / 2$ & Floresta & 0.20 & 0.42 & 0.05 & 0.13 & 0.20 & 3.2 & 2.7 & 1.4 & 2.0 & 2.3 & 17.9 & 28.6 & 28.7 & 19.8 & 23.7 \\
\hline II/6 & $\begin{array}{l}\text { Pastagem } \\
\text { nativa }\end{array}$ & 0.06 & 0.10 & 0.02 & 0.02 & 0.05 & 1.6 & 1.1 & 5.7 & 0.5 & 2.2 & 5.8 & 6.4 & 24.3 & 25.5 & 15.5 \\
\hline $1 \mathrm{I} / 8$ & Urbano & 0.97 & 0.04 & 0.11 & 0.19 & 0.33 & 6.4 & 2.9 & 4.5 & 6.7 & 5.1 & 25.2 & 12.7 & 28.2 & 15.6 & 20.4 \\
\hline $11 / 9$ & $\begin{array}{l}\text { Pastagem } \\
\text { nativa }\end{array}$ & 0.01 & 0.05 & 0.08 & 0.08 & 0.06 & 3.2 & 1.8 & 1.7 & 1.8 & 2.1 & 14.7 & 20.0 & 14.3 & 19.1 & 17.0 \\
\hline $\mathrm{II} / 10$ & Urbano & 0.06 & 0.07 & 0.05 & 0.06 & 0.06 & 3.1 & 2.4 & 3.2 & 3.8 & 3.1 & 13.4 & 14.6 & 16.1 & 12.2 & 14.1 \\
\hline $\begin{array}{l}\text { II/11- } \\
\text { direta }\end{array}$ & Urbano & 0.48 & 0.05 & 0.25 & 0.65 & 0.36 & 3.8 & 2.2 & 3.6 & 5.8 & 3.9 & 25.6 & 10.8 & 22.4 & 15.6 & 18.6 \\
\hline $\begin{array}{l}\text { II/11- } \\
\text { esquerda }\end{array}$ & Urbano & 0.11 & 0.79 & 0.07 & 1.27 & 0.56 & 2.0 & 2.2 & 1.9 & 2.2 & 2.1 & 25.3 & 10.7 & 11.5 & 8.2 & 13.9 \\
\hline III/7 & Floresta & 0.19 & 0.43 & 0.31 & 0.29 & 0.31 & 3.7 & 8.0 & 5.6 & 7.1 & 6.1 & 15.5 & 26.6 & 28.7 & 19.2 & 22.5 \\
\hline III/13 & Urbano & 0.19 & 0.14 & 0.35 & 0.76 & 0.36 & 6.8 & 2.8 & 2.6 & 3.9 & 4.0 & 11.2 & 15.2 & 21.8 & 12.3 & 15.2 \\
\hline $\mathrm{IV} / 14$ & Urbano & 0.85 & 0.64 & 1.14 & 1.74 & 1.09 & 4.6 & 3.2 & 3.8 & 5.8 & 4.3 & 39.7 & 20.1 & 27.0 & 22.4 & 27.3 \\
\hline IV/15 & Urbano & 0.84 & 0.55 & 0.90 & 2.06 & 1.09 & 4.8 & 3.7 & 5.0 & 7.6 & 5.3 & 26.2 & 21.1 & 30.3 & 26.2 & 26.0 \\
\hline IV/16 & Urbano & 0.98 & 1.10 & 1.30 & 1.61 & 1.25 & 6.7 & 6.2 & 4.4 & 6.3 & 5.9 & 38.9 & 34.4 & 29.0 & 33.6 & 34.0 \\
\hline $\begin{array}{l}\text { IV17- } \\
\text { direta }\end{array}$ & Urbano & 0.94 & 0.92 & 1.16 & 2.50 & 1.38 & 7.0 & 4.6 & 4.0 & 9.3 & 6.2 & 29.0 & 28.2 & 30.1 & 27.1 & 28.6 \\
\hline $\begin{array}{l}\text { IV/17- } \\
\text { esquerda }\end{array}$ & Urbano & 0.54 & 0.54 & 1.03 & 1.92 & 1.01 & 9.1 & 7.9 & 11.8 & 17.4 & 11.6 & 23.6 & 38.6 & 77.3 & 66.7 & 51.6 \\
\hline IV $/ 18$ & Urbano & 0.74 & 0.88 & 0.76 & 1.42 & 0.95 & 6.2 & 6.5 & 5.9 & 9.5 & 7.0 & 19.7 & 30.1 & 32.1 & 30.2 & 28.0 \\
\hline Média & Floresta & 0.09 & 0.16 & 0.09 & 0.11 & 0.11 & 3.2 & 3.5 & 2.6 & 3.0 & 3.1 & 12.1 & 14.5 & 14.0 & 9.7 & 12.6 \\
\hline Média & $\begin{array}{c}\text { Pastagem } \\
\text { nativa }\end{array}$ & 0.04 & 0.08 & 0.05 & 0.05 & 0.06 & 2.4 & 1.5 & 3.7 & 1.1 & 2.2 & 10.3 & 13.2 & 19.3 & 22.3 & 16.3 \\
\hline Média & Urbano & 0.61 & 0.52 & 0.65 & 1.29 & 0.77 & 5.5 & 4.1 & 4.6 & 7.1 & 5.3 & 25.3 & 21.5 & 29.6 & 24.6 & 25.2 \\
\hline Média & Total & 0.35 & 0.33 & 0.37 & 0.70 & 0.44 & 4.3 & 3.6 & 3.7 & 4.9 & 4.1 & 18.5 & 17.9 & 22.3 & 18.3 & 19.2 \\
\hline
\end{tabular}

\section{Carbono dissolvido na água (CDA)}

O teor de CDA variou entre 3,5 e 77,3 $\mathrm{mg} \mathrm{L}^{-1}$ (Tabela 2), da mesma maneira que ocorreu para o $\mathrm{P}$ e $\mathrm{K}$ solúveis na água, os maiores valores tenderam a ocorrer nos locais onde o curso do rio passava pela área urbana, antropizada. Com relação as formas de uso da terra, o teor de CDA no trecho do rio que passava pela área urbana foi duas vezes maior do que aquele que passava pela floresta e 1,6 vezes maior do que aquele que passava pela área de campo, na média dos locais e das épocas de coleta. Com isso se conclui que nos locais onde o rio passava pela área antropizada o livre lançamento de efluentes domésticos diretamente no seu leito acarretou aumento de concentração de $C$ na água. Essa é uma situação preocupante, pois se a concentração de CDA superar a capacidade assimilativa da água, causa prejuízos ambientais, tais como a eutrofização. Com relação à precipitação antes da amostragem, a grande quantidade de chuva que ocorreu para coleta de junho de 2017 (Tabela 1) não acarretou mudanças significativas na concentração de CDA.

De acordo com MEYBECK (1982), a concentração de carbono orgânico dissolvido nas águas de rios 
de regiões de clima temperado é da ordem de $3 \mathrm{mg} \mathrm{L}^{-1}$, representando cerca 38\% do CDA (LUDWIG et al. 1996). Conforme os autores, o CDA em águas de rios de clima temperado é entorno de $7,8 \mathrm{mg} \mathrm{L}^{-1}$. Foi possível constatar que as concentrações de CDA foram maiores na parte urbana do que nas demais formas de uso da terra (Tabela 2). ANDRADE (2008) também constatou diferenças significativas entre microbacias urbanizadas e microbacias florestadas para carbono dissolvido. Segundo o autor, as diferenças foram relacionadas às interferências antrópicas nas microbacias urbanas, devido principalmente ao aporte de efluentes domésticos.

\section{Fósforo extraível do solo (FES)}

O FES variou entre 0,5 e $96,7 \mathrm{mg} \mathrm{dm}^{-3}$ (Tabela 3), com os menores valores na área de uso com floresta. $\mathrm{Na}$ área urbanizada, a concentração foi 3,6 vezes maior do que na área de floresta e 2,2 vezes maior do que naquela de campo nativo, na média dos locais de coleta e das épocas de amostragem do solo. Isto demonstra que a antropização causada pela urbanização influenciou o teor de $\mathrm{P}$ também no solo às margens do ribeirão, em cujas margens provavelmente esse elemento esteja sendo depositado por ocasião das enchentes durante os períodos de elevado volume de chuva. Sobre a influência da pluviosidade antes da realização da amostragem (Tabela 1), ao comparar a concentração de FES para diferentes usos da terra nos períodos de agosto de 2016 e junho de 2017, é possível constatar que quanto maior foi a intensidade da chuva, maior foi ocorrência de perda de $\mathrm{P}$ em áreas de campo/floresta e aumento nas áreas urbanas, conforme Tabela 1.

Tabela 3. Valores de concentração de fósforo e potássio extraível e de matéria orgânica na camada de 0-3 $\mathrm{cm}$ do solo às margens do Ribeirão Petrópolis, em Lages, SC, divididos por grupo (G) formado com base na análise de agrupamento, para os 18 locais (L) de coleta.

\begin{tabular}{|c|c|c|c|c|c|c|c|c|c|c|}
\hline \multirow{2}{*}{$\mathrm{G} / \mathrm{L}$} & \multirow{2}{*}{ Land use } & \multicolumn{3}{|c|}{ Fósforo Renovável } & \multicolumn{3}{|c|}{ Potássio Renovável } & \multicolumn{3}{|c|}{ Matéria Orgânica } \\
\hline & & Ago-16 & Jun-17 & Média & Ago-16 & Jun-17 & Média & Ago-16 & Jun-17 & Média \\
\hline & & & --------- & m & $\mathrm{dm}^{-3}--\cdot$ & & & ---------- & \% -----. & - \\
\hline $1 / 1$ & Floresta & 14.0 & 8.4 & 11.2 & 78 & 87 & 83 & 4.3 & 3.9 & 4.1 \\
\hline $1 / 3$ & Floresta & 14.7 & 4.4 & 9.6 & 130 & 72 & 101 & 4.4 & 3.0 & 3.7 \\
\hline $1 / 4$ & Floresta & 2.3 & 0.5 & 1.4 & 79 & 87 & 83 & 2.8 & 3.3 & 3.1 \\
\hline $1 / 5$ & Floresta & 9.9 & 7.8 & 8.9 & 116 & 63 & 90 & 3.6 & 2.8 & 3.2 \\
\hline $\mathrm{l} / 12$ & Floresta & 12.5 & 5.3 & 8.9 & 99 & 69 & 84 & 3.2 & 2.5 & 2.9 \\
\hline $11 / 2$ & Floresta & 16.6 & 14.5 & 15.6 & 125 & 102 & 114 & 3.5 & 3.5 & 3.5 \\
\hline $11 / 6$ & Pastagem nativa & 29.1 & 18.0 & 23.6 & 152 & 98 & 125 & 6.2 & 5.4 & 5.8 \\
\hline II/8 & Urbano & 5.8 & 5.2 & 5.5 & 188 & 168 & 178 & 4.4 & 5.8 & 5.1 \\
\hline $11 / 9$ & Pastagem nativa & 8.9 & 10.3 & 9.6 & 198 & 107 & 153 & 4.5 & 4.9 & 4.7 \\
\hline $\mathrm{II} / 10$ & Urbano & 3.0 & 5.7 & 4.4 & 124 & 144 & 134 & 3.8 & 4.8 & 4.3 \\
\hline $\mathrm{II} / 11$ & Urbano & 8.6 & 19.1 & 13.9 & 100 & 93 & 97 & 3.2 & 4.3 & 3.8 \\
\hline $\mathrm{III} / 7$ & Floresta & 14.0 & 19.7 & 16.9 & 732 & 312 & 522 & 6.5 & 6.9 & 6.7 \\
\hline III/13 & Urbano & 12.1 & 96.7 & 54.4 & 438 & 330 & 384 & 2.4 & 3.7 & 3.1 \\
\hline $\mathrm{IV} / 14$ & Urbano & 88.4 & 79.7 & 84.1 & 366 & 216 & 291 & 4.3 & 3.9 & 4.1 \\
\hline IV/15 & Urbano & 23.1 & 63.6 & 43.4 & 300 & 175 & 238 & 1.2 & 2.0 & 1.6 \\
\hline IV/16 & Urbano & 54.3 & 62.8 & 58.6 & 348 & 107 & 228 & 2.8 & 2.7 & 2.8 \\
\hline IV/17 & Urbano & 35.3 & 20.7 & 28.0 & 56 & 123 & 90 & 3.2 & 5.0 & 4.1 \\
\hline $\mathrm{IV} / 18$ & Urbano & 31.2 & 43.6 & 37.4 & 177 & 138 & 158 & 2.0 & 2.2 & 2.1 \\
\hline Médias & Foresta & 12.0 & 8.7 & 10.3 & 194 & 113 & 154 & 4.0 & 3.7 & 3.9 \\
\hline Médias & Pastagem nativa & 19.0 & 14.2 & 16.6 & 175 & 103 & 139 & 5.4 & 5.2 & 5.3 \\
\hline Médias & Urbano & 29.1 & 44.1 & 36.6 & 233 & 166 & 200 & 3.0 & 3.8 & 3.4 \\
\hline Médias & Total & 21.3 & 27.0 & 24.2 & 211 & 138 & 175 & 3.7 & 3.9 & 3.8 \\
\hline
\end{tabular}

Os valores de FES encontrados na área urbana nesta pesquisa variaram de 4,4 a $84,1 \mathrm{mg} \mathrm{dm}^{-3}$, com média de $36,6 \mathrm{mg} \mathrm{dm}^{-3}$, portanto, expressivamente maiores do que os verificados por SZYMCZAK et al. (2013) que foram da ordem de 3,0 a $10,9 \mathrm{mg} \mathrm{dm}^{-3}$ também em área urbanizada às margens da Sanga Lagoão do Ouro, RS. Para área de floresta, a concentração de FES (Tabela 3) teve uma variação de 1,4 a $16,9 \mathrm{mg} \mathrm{dm}^{-3}$, com média de $10,3 \mathrm{mg} \mathrm{dm}^{-3}$, desta maneira maiores que os determinados por OLIVEIRA (2010) cuja ordem é de $4,90 \mathrm{mg} \mathrm{dm}^{-3}$ na camada de $0-5 \mathrm{~cm}$, para o mesmo tipo de floresta. KEMERICH et al. (2012), no trecho de mata nativa do rio Vacacaí Mirim determinou concentrações de FES na ordem de $2,0 \mathrm{mg} \mathrm{dm}^{-3}$, enquanto, no trecho de campo nativo os valores encontrados situaram na faixa de $1,5 \mathrm{mg} \mathrm{dm}^{-3}$. Assim, a grande maioria dos valores de concentração de FES encontrados no solo na bacia do Ribeirão Petrópolis foi maior do que os verificados por esses autores, demonstrando, assim, a grande variabilidade espacial e temporal nesses dados.

Potássio extraível do solo (PES)

O teor PES variou entre 56 e $732 \mathrm{mg} \mathrm{dm}^{-3}$ (Tabela 3), considerando as formas de ocupação da terra e 
as épocas de coleta das amostras de solo, com os menores valores na área de campo. Na área urbanizada, a concentração foi 1,4 vezes maior do que na área de campo e 1,3 vezes maior do que na área ocupada por floresta nativa, na média dos locais de coleta e das épocas de amostragem do solo. Isto demonstra a influência antrópica na área urbana para teores de $\mathrm{K}$ no solo às margens do curso hídrico, cujo aporte desse elemento para as margens pode ter ocorrido durante os regimes de cheia. Entretanto conforme pluviosidade ocorrida antes da amostragem para junho de 2017 (Tabela 1), ainda existe a possibilidade que épocas com forte incidência pluviométrica acarrete na elevação da velocidade do curso hídrico fazendo com que PES presente na camada mais superficial do solo das margens seja removido.

Ao comparar os valores encontrados com resultados obtidos por outros autores, KEMERICH et al. (2012), encontraram valores próximo de zero para PES dentro da área urbana na bacia do rio VacacaíMirim, resultado que não corrobora com os da bacia do Ribeirão Petrópolis. Na área de floresta, foram determinadas concentrações de PES (Tabela 3) que variaram de 83 a $522 \mathrm{mg} \mathrm{dm}^{-3}$, com média de $154 \mathrm{mg}$ $\mathrm{dm}^{-3}$, desta maneira menores que os determinados por OLIVEIRA (2010) que foram da ordem de $312 \mathrm{mg}$ $\mathrm{dm}^{-3}$ para camada de $0-5 \mathrm{~cm}$, para o mesmo tipo de floresta.

Entretanto, concentrações inferiores foram encontradas por KEMERICH et al. (2012) para mata nativa, na ordem de $96 \mathrm{mg} \mathrm{dm}{ }^{-3}$, e por OLIVEIRA et al. (2016) para área de floresta amazônica com influência de disposição de resíduos sólidos urbanos, na ordem de $29 \mathrm{mg} \mathrm{dm}^{-3}$ para camada de $0-20 \mathrm{~cm}$. Na área de campo, as concentrações de PES nesta pesquisa variaram de 125 a $153 \mathrm{mg} \mathrm{dm}^{-3}$, com média de $139 \mathrm{mg} \mathrm{dm}^{-3}$ (Tabela 3), distinguindo de KEMERICH et al. (2012) e OLIVEIRA et al. (2016) encontraram concentrações inferiores, respectivamente, na ordem $30 \mathrm{mg} \mathrm{dm}^{-3}$ para camada de $0-5 \mathrm{~cm}$ e $19 \mathrm{mg} \mathrm{dm}^{-3}$ para camada de $0-20 \mathrm{~cm}$.

\section{Matéria orgânica do solo (MOS)}

A MOS variou entre 1,2\% e 6,9\%, com os menores valores na área urbana (Tabela 3). Na área ocupada pela urbanização, a concentração foi 1,53 vezes menor do que na área ocupada por campo e 1,13 vezes menor do que naquela ocupada por floresta, na média dos locais de coleta e das épocas de amostragem do solo. Isto demonstra certa influência da antropização na concentração de $C$ no solo. Entretendo, esses resultados demonstraram que o teor de MOS não se relacionou estreitamente com uso e ocupação da terra e que possivelmente dependeu mais das características do solo em cada local avaliado. Com relação as diferentes épocas do ano, não foi constatado mudanças significativas entre elas.

Os valores de MOS encontrados nesta pesquisa foram maiores que os verificados por SZYMCZAK et al. (2013) que variaram de 1,04 a 2,43\% para solo as margens da Sanga Lagoão do Ouro em uma área urbana permeada com campos e lavouras, sujeita a acúmulo de lixo e lançamento de esgotos. Também foram superiores aos resultados obtidos por KEMERICH et al. (2012) ao caracterizar o solo da bacia do rio Vacacaí-Mirim (1.146 km²) sob diferentes usos, onde o teor de MOS foi maior para mata nativa com 1,64\% seguido do campo nativo com $1,3 \%$ e área urbana com $1 \%$.

\section{Agrupamento dos dados}

A distribuição dos pontos de coleta do solo e da água formaram quatro grupos, resultando em padrões de características semelhantes dentro de cada grupo e de diferentes características entre um e outro grupo (Tabela 4). No grupo I encontravam-se os pontos 1, 3, 4, 5 e 12, no grupo II os pontos 2, 6, 8, 9, 10 e 11, o grupo III compreendeu os pontos 7 e 13 e o grupo IV englobou os pontos 14, 15, 16, 17 e 18. A principal explicação para a semelhança de características entre os pontos de coleta dentro de cada grupo, e de distinção entre os grupos, tanto para o solo quanto para a água, é a variação de uso da terra. As características de cada um dos grupos estudados são descritas a seguir.

O grupo I correspondeu aos pontos que estavam localizados na área de floresta onde havia pequena ou nenhuma interferência antrópica, com concentração de FES menor do que nos outros grupos, entre 0,5 a $14,7 \mathrm{mg} \mathrm{dm}^{-3}$, e de PES, entre 63 a $130 \mathrm{mg} \mathrm{dm}^{-3}$. Com relação a água, no grupo I enquadraram-se as amostras cujo teor de FDA variou entre 0,02 a $0,22 \mathrm{mg} \mathrm{L}^{-1}$, PDA entre 3 a $14,2 \mathrm{mg} \mathrm{L}^{-1}$ e o CDA entre 3,45 a $20,36 \mathrm{mg} \mathrm{L}^{-1}$.

O grupo II correspondeu aos locais que se situavam na área de floresta com interferência antrópica, aos de campo com aspecto alterado principalmente pela queima e à área urbana localizada a montante da bacia. O FES apresentou, para esse grupo, concentrações variando entre 3 a $29,1 \mathrm{mg} \mathrm{dm}^{-3}$, enquanto o PES variou entre 29,1 a $198 \mathrm{mg} \mathrm{dm}^{-3}$. Para água do grupo II, o teor de FDA variou entre 0,01 a $1,27 \mathrm{mg} \mathrm{L}^{-1}$, o PDA entre 1,20 a $16,8 \mathrm{mg} \mathrm{L}^{-1}$ e o CDA entre 5,83 a $28,63 \mathrm{mg} \mathrm{L}^{-1}$.

O grupo III correspondeu aos locais 7 e 13 e que respectivamente estavam localizados em área de floresta com lançamento de efluentes domésticos a montante e área urbana. O FES apresentou teores entre 12,1 a $96,7 \mathrm{mg} \mathrm{dm}^{-3}$ enquanto o PES variou entre 312 a $732 \mathrm{mg} \mathrm{dm}^{-3}$. $\mathrm{Na}$ água do grupo III, a concentração 
de FDA variou entre 0,14 a $0,76 \mathrm{mg} \mathrm{L}^{-1}$, PDA entre 6,4 a $20 \mathrm{mg} \mathrm{L}^{-1}$ e CDA entre 11,24 a 28,69 $\mathrm{mg} \mathrm{L}^{-1}$.

Tabela 4. Resultado da análise de agrupamento dos pontos de amostragem de solo e água, obtido pelo método hierárquico.

\begin{tabular}{cccc}
\hline Grupo I & Grupo II & Grupo III & Grupo IV \\
\hline 1 & 2 & 7 & 14 \\
3 & 6 & 13 & 15 \\
4 & 8 & - & 16 \\
5 & 9 & - & 17 \\
12 & 10 & - & 18 \\
- & 11 & - & - \\
\hline
\end{tabular}

O grupo IV correspondeu aos pontos urbanos que se situavam mais próximos do exutório da bacia. A concentração de FES apresentou variação de 20,7 a $88,4 \mathrm{mg} \mathrm{dm}^{-3}$ e PES de 56 a $366 \mathrm{mg} \mathrm{dm}^{-3}$. Para a água das amostras do grupo IV, o teor de FDA variou entre 0,54 a 1,30 $\mathrm{mg} \mathrm{L}^{-1}$, o de PDA entre 7,9 a 43,4 $\mathrm{mg} \mathrm{L}^{-1} \mathrm{e}$ o de CDA entre 19,68 a $77,29 \mathrm{mg} \mathrm{L}^{-1}$.

Para os locais do grupo I, em ambiente florestal, sem ação antrópica, a principal fonte de origem para liberação desses nutrientes ao solo foi a decomposição da serapilheira com consequente mineralização da matéria orgânica, segundo constatações de DINIZ et al. (2015). Já na área urbana no grupo II, III e IV, o FDA e CDA apresentaram altas concentrações devido ao lançamento de efluentes sanitários com detergentes fosfatados diretamente no leito do rio, provavelmente pela via do sistema de drenagem pluvial.

Para o caso do PDA, a concentração de $\mathrm{K}$ em águas naturais é normalmente baixa, menor do que 10 $\mathrm{mg} \mathrm{L}^{-1}$, pois as rochas que contêm $\mathrm{K}$ são relativamente resistentes à intemperização (CETESB 2017). Os locais na floresta em que a água apresentou valores de $\mathrm{K}$ acima de $10 \mathrm{mg} \mathrm{L}^{-1}$, como aqueles encontrados no grupo I, isso foi devido, possivelmente, à queima da biomassa vegetal a montante que mineralizou o elemento e o liberou para ser transportado pela enxurrada para as águas do ribeirão. A enxurrada decorrente das chuvas e a elevada declividade do terreno, com a vegetação queimada, podem ter contribuído para a movimentação da cinza resultante da queima, depositando-a nas áreas baixas onde se realizaram as coletas de amostras para este estudo, de acordo com o que foi observado também por BARROSO et al. (2017). Em locais urbanos como os do grupo IV, a emissão de efluentes com sabões ricos em sais de $\mathrm{K}$ é uma das principais fontes antrópicas nesse meio, conforme constatado por OSORIO \& OLIVEIRA (2001). Segundo BERNER \& BERNER (2012), estima-se que no mundo cerca de $7 \%$ do $\mathrm{K}$ presente nas águas dos rios provém da poluição.

Para os locais 2 e 7, mesmo estando em área de floresta apresentaram altas concentrações de FDA, PDA e CDA que provavelmente foram originárias do aporte antrópico a montante dos referidos locais amostrados.

Para o caso do grupo II, o FES e PES presente no solo na área urbana era provavelmente oriundo das áreas de floresta e campo nativo próximas desses locais, devido ao alto teor de matéria orgânica nessas áreas. Segundo MACHADO (2012), o P está presente no solo em sua maior parte (67 a $71 \%$ ) na forma orgânica, e a decomposição de resíduos orgânicos com consequente mineralização da matéria orgânica pode liberar o elemento ao solo. No grupo III, a alta concentração de PES, no local 7, foi provavelmente influenciada pelas propriedades químicas do solo, enquanto, no local 13, as concentrações de FES e PES relacionaram-se à deposição de nutrientes durante regime de cheias do rio. Para o grupo IV, a concentração de FES e PES também foi dependente da possível deposição desses nutrientes em momentos de cheias do rio.

Os resultados da Tabela 1 demonstraram que os teores de MOS não apresentaram relação forte com uso e ocupação da terra, e que, possivelmente, dependeram mais das características do solo em cada local avaliado do que dos usos da terra estudados. Os pontos 6 e 7, presentes respectivamente na área de campo e floresta, foram os que apresentaram os maiores teores de MOS, na média dos períodos, demonstrando a possibilidade destas concentrações estarem mais relacionadas a fatores naturais do que ao aporte antrópico. Já os locais 15 e 18, situados na área urbana, apresentaram os menores teores de MOS, indicando a possível influência da falta de cobertura vegetal, o que fez com que o solo, totalmente exposto à ação da chuva e enxurrada a ela associada, contribuísse para esse resultado.

\section{Matriz de correlação}

Para agosto de 2016 , verificou-se que $26,7 \%$ das correlações foram significativas ao nível de $1 \%$ e $6,7 \%$ significativas ao nível de $5 \%$ e que os parâmetros PES e MOS não correlacionaram com as demais variáveis analisadas (Tabela 5). O CDA, FDA e FES, por outro lado, correlacionaram-se entre si. Isto era Rev. Ciênc. Agrovet., Lages, SC, Brasil (ISSN 2238-1171) 
esperado, segundo FRAGOSO JÚNIOR et al. (2009) a MO presente na água é uma das fontes de $\mathrm{C}$ e $\mathrm{P}$ nesse meio. Dessa maneira, em muitos locais o $\mathrm{P}$ presente na água foi depositado no solo às margens devido ao regime de cheias. Também se observou uma forte correlação do CDA, FDA e PDA, entre si, podendo ser explicada pela presença do $\mathrm{P}$ e $\mathrm{K}$ em detergentes e sabões oriundos da área urbana $\mathrm{e}$ descartados na água do rio por meio de esgoto doméstico.

Tabela 5. Matriz de correlação dos valores de parâmetros analisados nas amostras de solo e água para agosto de 2016, na bacia hidrográfica do Ribeirão Petrópolis.

\begin{tabular}{|c|c|c|c|c|c|c|}
\hline & FDA & FES & PDA & PES & CDA & MOS \\
\hline FDA & 1,00 & & & & & \\
\hline FES & $0,59^{*}$ & 1,00 & & & & \\
\hline PDA & 0,70 & $0,24^{\mathrm{ns}}$ & 1,00 & & & \\
\hline PES & $0,34^{\mathrm{ns}}$ & $0,37^{\text {ns }}$ & $0,22^{\text {ns }}$ & 1,00 & & \\
\hline CDA & $0,79^{x *}$ & $0,64^{x \pi}$ & $0,72^{\pi \times}$ & $0,34^{\mathrm{ns}}$ & 1,00 & \\
\hline MOS & $-0,40^{\mathrm{ns}}$ & $-0,03^{\mathrm{ns}}$ & $-0,46^{\text {ns }}$ & $0,36^{\text {ns }}$ & $-0,38^{\text {ns }}$ & 1,00 \\
\hline
\end{tabular}

${ }^{*}$ significativo $(\mathrm{p}<0,05)$; ${ }^{*}$ significativo $(\mathrm{p}<0,01)$; ns: não significativo. FDA: fósforo dissolvido na água; FES: fósforo extraível do solo; PDA: potássio dissolvido na água; PES: potássio extraível do solo; CDA: carbono dissolvido na água; MOS: matéria orgânica do solo.

Para junho de 2017 , verificou-se que $26,7 \%$ das correlações foram significativas ao nível de $1 \%$ e $26,67 \%$ ao nível de 5\% (Tabela 6). Todos os parâmetros apresentaram correlação com alguma variável. Nessa data também foi constatada a presença de correlação do FDA e CDA com FES e PDA. Também foi observada a correlação de PES com MOS e PDA, indicando efeito do clima nesse período (outono) sobre essas variáveis. A falta de correlação entre PDA e MOS pode estar relacionada com diferentes tempos de transformação entre etapas.

Tabela 6. Matriz de correlação dos valores de parâmetros analisados nas amostras de solo e água para junho de 2017, na bacia hidrográfica do Ribeirão Petrópolis.

\begin{tabular}{lcccccc}
\hline & FDA & FES & PDA & PES & CDA & MOS \\
\hline FDA & $1,00{ }^{* *}$ & & & & & \\
FES & $0,94^{* *}$ & 1,00 & & & & \\
PDA & $0,71^{\text {ns }}$ & $0,60^{\text {ns }}$ & 1,00 & & & \\
PES & $0,33^{\text {ns }}$ & $0,41^{\text {ns }}$ & $0,62^{*}$ & 1,00 & & \\
CDA & $0,67^{* *}$ & $0,75^{\text {*n }}$ & $0,54^{*}$ & $0,39^{\text {ns }}$ & 1,00 & 1,00 \\
MOS & $-0,43^{\text {ns }}$ & $-0,32^{\text {ns }}$ & $-0,12^{\text {ns }}$ & $0,53^{*}$ & $-0,04^{\text {ns }}$ & 1,00 \\
\hline
\end{tabular}

*significativo $(p<0,05)$; ${ }^{*}$ significativo $(p<0,01)$; ns: não significativo. FDA: fósforo dissolvido na água; FES: fósforo extraível do solo; PDA: potássio dissolvido na água; PES: potássio extraível do solo; CDA: carbono dissolvido na água; MOS: matéria orgânica do solo.

Considerando todo período de pesquisa, verificou-se que 33,3\% das correlações foram significativas ao nível de $1 \%$ e 13,3\% ao nível de $5 \%$ (Tabela 7 ). O parâmetro MOS não correlacionou com as demais variáveis analisadas. Na média dos períodos foi constatada correlação do FDA e CDA com FES e PDA. Também foi observada correlação do PDA e CDA com PES, indicando a possibilidade de que o $\mathrm{K}$ presente em sabões e que estava no esgoto também tivesse sido depositado no solo.

Tabela 7. Matriz de correlação dos valores de parâmetros analisados nas amostras de solo e água para a média dos resultados de agosto de 2016 e junho de 2017, na bacia hidrográfica do Ribeirão Petrópolis.

\begin{tabular}{lcccccc}
\hline & FDA & FES & PDA & PES & CDA & MOS \\
\hline FDA & 1,00 & & & & & \\
FES & $0,88^{\text {** }}$ & 1,00 & & & & \\
PDA & $0,71^{\text {** }}$ & $0,47^{\text {ns }}$ & 1,00 & & & \\
PES & $0,42^{\text {ns }}$ & $0,42^{\text {ns }}$ & $0,62^{*}$ & 1,00 & & \\
CDA & $0,86^{* *}$ & $0,75^{* \pi}$ & $0,71^{* *}$ & $0,56^{*}$ & 1,00 & \\
MOS & $-0,45^{\text {ns }}$ & $-0,24^{\text {ns }}$ & $-0,18^{\text {ns }}$ & $0,43^{\text {ns }}$ & $-0,17^{\text {ns }}$ & 1,00 \\
\hline
\end{tabular}

${ }^{*}$ significativo $(p<0,05)$; ${ }^{* *}$ significativo $(p<0,01)$; ns: não significativo. FDA: fósforo dissolvido na água; FES: fósforo extraível do solo; PDA: potássio dissolvido na água; PES: potássio extraível do solo; CDA: carbono dissolvido na água; MOS: matéria orgânica do solo. 


\section{CONCLUSÃO}

Dentre as seis variáveis analisadas, a concentração de fósforo, potássio e carbono dissolvido na água e de fósforo e potássio extraível no solo foi maior na área urbana devido ao esgoto doméstico sem qualquer tratamento que é lançado na água e atinge o solo às margens do ribeirão. Apesar da concentração de MOS apresentar na área urbana um menor teor, os resultados demonstraram que o teor de MOS não se relacionou estreitamente com uso e ocupação da terra e que possivelmente dependeu mais das características do solo em cada local avaliado.

Para fósforo e potássio presente na água e no solo das margens da área urbana, a ocorrência de forte precipitação tem efeito prolongado sobre a concentração nesses parâmetros. O carbono e fósforo dissolvido na água se correlacionaram com o fósforo extraível do solo e potássio dissolvido, nas duas épocas do ano e nas médias do período de estudo, enquanto, o potássio extraível do solo se correlacionou com o potássio dissolvido na água e a matéria orgânica do solo, para o outono, indicando efeito do clima nessa correlação. Também foi observado para média dos períodos a correlação do potássio dissolvido na água e carbono dissolvido na água com potássio extraível do solo, indicando a existência da possibilidade de que o $\mathrm{K}$ presente em sabões e que está no esgoto também seja depositado no solo.

A pesquisa aponta que o aporte de FDA, FES, PDA, PES e CDA é alto no trecho da área urbana, e se deve ao esgoto doméstico sem qualquer tratamento que é lançado na água e atinge o solo às margens do ribeirão.

\section{AGRADECIMENTOS}

Ao Conselho Nacional de Desenvolvimento Científico e Tecnológico (CNPq), pelo aporte de recursos financeiro que custearam a pesquisa. Ao Município de Lages pelo incentivo dado à capacitação.

\section{REFERÊNCIAS}

ALVIM RB. 2016. Dinâmica do nitrogênio e fósforo em águas fluviais de uma bacia hidrográfica com diferentes usos do solo no sudeste do Brasil. Tese (Doutorado em Geociências). Niterói: UFF. 143p.

ANDRADE TMB de. 2008. Dinâmica das formas dissolvidas de nitrogênio e carbono em microbacias da Mata Atlântica no município de Ubatuba (SP). Dissertação (Mestrado do Curso de Mestrado em Ecologia Aplicada). Piracicaba: USP. 100p.

BARROSO DFR et al. 2017. Impactos de diferentes usos da terra sobre os recursos hídricos em microbacias no Nordeste Paraense na Amazônia Oriental. In: VASCONCELOS SS et al. (Org.). Amazônia em tempo: impactos do uso da terra em diferentes escalas. Belém: Embrapa Amazônia Oriental. p. 339-368.

BERNER EK \& BERNER RA. 2012. Global environment: water, air, and geochemical Cycles. 2.ed. Princeton: Princeton University Press.

BRASIL. 2005. Resolução №. 357, de 17 de março de 2005. Dispõe sobre a classificação dos corpos de água e diretrizes ambientais para o seu enquadramento bem como estabelece condições e padrões de lançamento de efluentes e dá outras providências. Brasília: DF. (Diário Oficial da República Federativa do Brasil).

CETESB. 2017. Companhia Ambiental do Estado de São Paulo. Qualidade das Águas Doces no Estado de São Paulo. São Paulo: CETESB.

CARVALHO RG de. 2014. As bacias hidrográficas enquanto unidades de planejamento e zoneamento ambiental no Brasil. Presidente Prudente: Caderno Prudentino de Geografia 36. p.26-43.

CEMADEN. Dados pluviométricos: Lages (SC). Disponível em: http://www.cemaden.gov.br/mapainterativo/\#. Acesso em: 06 jul. 2018.

DINIZ AR et al. 2015. Biomassa, estoque de carbono e de nutrientes em estádios sucessionais da Floresta Atlântica, RJ. Revista Brasileira de Ciências Agrárias 10: 443-451.

FRAGOSO JÚNIOR CR et al. 2009. Modelagem ecológica em ecossistemas aquáticos. São Paulo: Oficina de Textos. 10p.

KEMERICH PD et al. 2012. Caracterização física e química do solo sob diferentes usos em bacia hidrográfica. Revista do Departamento de Geografia da USP 24: 92-107.

LUDWIG W et al. 1996. River discharges of carbon to the world's oceans: determining local inputs of alkalinity and of dissolved and particulate organic carbon. Comptes Rendus de L'academie Des Sciences 19: 1007-1014.

PAULA FCF de et al. 2010. Emissões naturais e antrópicas de metais e nutrientes para a bacia inferior do rio de contas, Bahia. Química Nova 33: 70-75.

MACHADO LO. 2012. Adubação fosfatada. Informativo. Disponível em: http://www.dpv24.iciag.ufu.br. Acesso em: 07 abr. 2018.

MEYBECK M. 1982. Carbon, nitrogen, and phosphorus transport by world rivers. American Journal of Science 282: 401 450.

MURPHY J \& RILEY JP. 1962. A modified single solution method for the determination of phosphate in natural waters. Analytica Chimica Acta 27: 31-36. 
OLIVEIRA BOS de et al. 2016. Avaliação dos solos e das águas nas áreas de influência de disposição de resíduos sólidos urbanos de Humaitá, Amazonas. Engenharia Sanitária e Ambiental 21: 593-601.

OLIVEIRA LP de. 2010.Carbono e nutrientes no solo e na serapilheira em Floresta Ombrófila Mista Montana e plantio de Pinus elliottii Engelm. Dissertação (Mestrado do Curso de Programa de Pós-graduação em Ciências Florestais). Irati: Unicentro. 64p.

OISHI MK. 1996. Caracterização do meio físico, das características físicas e químicas e de fluxo de nutrientes em tributários da bacia hidrográfica do reservatório de Barra Bonita (Médio Tietê - SP). Tese (Doutorado em Ciências Ambientais). São Carlos: Escola de Engenharia de São Carlos. 199p.

OSORIO VKL \& OLIVEIRA W de. 2001. Polifosfatos em detergentes em pó comerciais. Química Nova 24: $700-708$.

QUEVEDO CMG de \& PAGANINI WS. 2011. Impactos das atividades humanas sobre a dinâmica do fósforo no meio ambiente e seus reflexos na saúde pública. Ciência \& Saúde Coletiva 16: 3539-3539.

SANTOS JS dos et al. 2009. Parâmetros indicativos do processo de salinização em rios urbanos do semi-árido brasileiro. Química Nova 32: 1534-1538.

SANTOS UM et al. 1984. Rios da Bacia Amazônica. I. Afluentes do rio Negro. Acta Amazônica 14: $222-237$.

SEQUINEL $R$ et al. 2011. Análise química das águas do rio Verde: uma correlação entre atividades humanas e as concentrações de íons NO3- , PO43- , K+, Ca2+ e Mg2+. Publicativo EUPG - Ciências Exatas e da Terra, Agrárias e Engenharias 17: 29-37.

SILVA AR da \& FONSECA ALD. 2016. Eutrofização dos recursos hídricos como ferramenta para a compreensão das doenças de vinculação hídrica. Geosul 31: 247-270.

SOUZA JCR de \& ALMEIDA RA de. 2010. Vazantes e enchentes na Amazônia Brasileira: impactos ambientais, sociais e econômicos. In: VI Seminário Latino-Americano de Geografia Física e II Seminário Ibero-Americano de Geografia Física da Universidade de Coimbra. Resumos...Coimbra: Universidade de Coimbra.

SZYMCZAK DA et al. 2013. Qualidade química do solo com diferentes níveis de degradação em área de preservação permanente. Revista Monografias Ambientais 10: 2158-2169.

TEDESCO MJ et al. 1995. Análises de solo, plantas e outros materiais. 2.ed. Porto Alegre: UFRGS. 174p.

VON SPERLING M. 2005. Introdução à qualidade das águas e ao tratamento de esgotos. Princípios do tratamento biológico de águas residuárias. 3.ed. Belo Horizonte: UFMG. 452p. 